\title{
Not in the Brochure: Porneia and Residential Aged Care
}

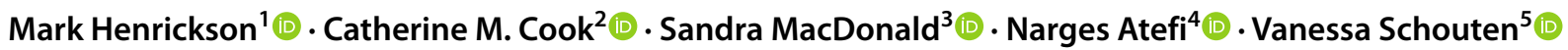

Accepted: 25 March 2021 / Published online: 31 March 2021

(c) The Author(s), under exclusive licence to Springer Science+Business Media, LLC, part of Springer Nature 2021

\begin{abstract}
Introduction Sexuality and intimacy in residential aged care (RAC) are receiving increased research attention. In this article, porneia refers to access to sex workers, as well as online pornography, and masturbation by residents in RAC. Sex work is legal and regulated in Aotearoa New Zealand.

Methods The present study was a two-arm mixed-method cross-sectional study using a concurrent triangulation design. A validated survey tool was developed. Data were collected in 2018-2019: 433 staff surveys were collected from 35 RAC across the country; 61 interviews were carried out with 77 staff, residents, and family members.

Results Staff opinions about sex work and pornography were inconclusive. Nevertheless, access to sex workers occurs in many RAC facilities across the country. Interviews demonstrated a diversity of responses among the three groups; staff attitudes are paramount.

Conclusions Some staff are prepared for resident requests for sex workers; others continue to look to policies and management for guidance, but such policies are often lacking. Most staff have adopted the language of needs vs. rights which dominates the literature.

Policy Implications Staff education on sexuality and facility policy is essential; education for residents and their families is also desirable. Facilities often over-notify third parties. Discourse about sexuality needs to move towards a person-centred, salutogenic approach.
\end{abstract}

Keywords Ageing $\cdot$ Pornography $\cdot$ Prostitution $\cdot$ Residential aged care $\cdot$ Sex work $\cdot$ Sexuality

Mark Henrickson

m.henrickson@massey.ac.nz

Catherine M. Cook

catherine.cook@aut.ac.nz

Sandra MacDonald

saymac@xtra.co.nz

Narges Atefi

n.atefi@massey.ac.nz

Vanessa Schouten

v.schouten@massey.ac.nz

1 School of Social Work, Massey University, Private Bag 102904, North Shore MSC, Auckland 0745, New Zealand

2 School of Clinical Sciences, Nursing Department, AUT University, Auckland, New Zealand

3 School of Nursing, Manukau Institute of Technology, Auckland, New Zealand

4 School of Social Work, Massey University, Auckland, New Zealand

5 School of Humanities, Massey University, Palmerston North, New Zealand

\section{Introduction}

Sexuality and intimacy in residential aged care (RAC) have received increasing research attention in the last 5 years (Aguilar, 2017; Bauer et al., 2019; Gewirtz-Meydan et al., 2019). It is clear that this is a policy, research, and practice area that requires urgent attention by residential care providers and regulators, and even by residents and their family members (Brassolotto et al., 2020; Cook et al., 2018). What has previously been an unspeakable area is now being more openly spoken about, at least by researchers (Simpson et al., 2017a, b) and residents (Frankowski \& Clark, 2009; Simpson et al., 2018), and some facility managers and staff (Thys et al., 2019). The present national study on the ethics of consent in intimacy in sexuality in RAC was undertaken in Aotearoa New Zealand, and a comprehensive report is available at https://mro.massey.ac.nz/handle/10179/15720. In general, the literature has found that expressions of sexuality and intimacy, particularly between opposite-sex residents (or residents and their non-resident opposite-sex partners), have 
become more acceptable in RAC, or at least RAC staff have found it more difficult to avoid the questions. Other expressions remain less acceptable and even unspeakable (Howard et al., 2019). We address our findings on same-sex intimacy elsewhere. The taxonomy of 'aged care' is evolving; here, we have chosen to retain the usage most common in our national and regional context.

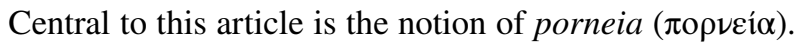
The word and its cognates is a word from ancient Greek which means prostitution, unchastity, fornication, and every kind of sexual intercourse outside of marriage (Arndt \& Gingrich, 1979); in this article, it refers more specifically to resident access to sex workers, online pornography, and masturbation. Aotearoa New Zealand decriminalised and regulated most sex work in 2003 (Bellamy, 2012; New Zealand Parliament, (2003); New Zealand Prostitutes Collective [NZPC], n.d.). It remains illegal to coerce someone into sex work, for a third party to facilitate sex work by someone under the age of 18 , or to engage in sex work on a temporary visa (such as a visitor or student visa). Brothel operators are regulated by the Ministry of Justice, and the 2003 Act is enforced by the Ministry of Health and the Labour Inspectorate. Although legalisation and regulation have not removed social stigma, when we discuss access to sex workers in this article, we are discussing an entirely legal and regulated activity. We recognise that this will not be true in all jurisdictions. We also take for granted that any paid sexual activity will be mutually consenting and 'safe' from a public health perspective. It is beyond our scope to engage in the debate around the relative merits of sex work itself, although we acknowledge that such debates exist.

This study arose in part because (prior to the study) some of the authors were invited to speak at staff development events at care homes, and national conferences about sexuality and intimacy in residential care. At these events, we were told very privately by some RAC staff that their facility offered access to sex workers, but that such access would never be publicly acknowledged for fear of being singled out by prurient mainstream and social media, or shunned by some potential residents and their families. The reputational risk, and implications for the loss of business, was too great. This is probably not an unfounded concern. What we have discovered in our study is that access to sex work, and staff willingness to facilitate resident access to sex workers, is much more widespread than has been publicly acknowledged, or put in any marketing brochure or list of offerings of an RAC. It is our hope to contribute to normalising the discourse and policy around access to sex workers, and perhaps to begin to destigmatise the few RAC facilities which are brave enough to acknowledge publicly that they are doing what a number of other RAC facilities are doing quietly. Our research questions in this article ask to what extent access to sex work is being provided in RAC in Aotearoa New Zealand: what are staff, resident, and family attitudes towards sex work for residents in RAC? What are the policy implications of the answers to these questions?

Aotearoa New Zealand is a multicultural nation of five million people on two main islands in the southwestern Pacific Ocean. According to the 2018 Census, 3.3 million people (70.2\% of the population) identified with at least one European ethnicity (in other nations, this ethnicity may be known as 'Caucasian', or 'White', or similar). The next largest group is the indigenous Māori, who represent $16.5 \%$ of the population; the third largest is 'Asian' which represent $15.1 \%$ of the population (the largest subgroups are Chinese, Indian, and Pilipinx). Pacific peoples make up $8.1 \%$ of the population (major subgroups are Samoan, Tongan, and Cook Island Māori, although many other groups exist, some in numbers larger than the populations of the island nations), and 1.5\% of the population identify as Middle Eastern/Latin American/ African (StatsNZ/Tatauranga Aotearoa, 2019). The population aged 65 and older is expected to increase from $13 \%$ of the total population in 2009 to $21 \%$ by 2031 (Ministry of Social Development/Te Manatu Whakahiato Ora, n.d.).

\section{Literature}

A literature search highlighted the paucity of research that specifically addresses sex work and older adults in residential care. The literature on intimacy and sexuality generally has grown markedly over the last 3 years, and it is clear that this is an area that is of increasing importance to researchers, practitioners, and policy makers. A debate has been framed to take a position on whether intimacy and sexuality in RAC are needs or rights (Bauer et al., 2013; Rowntree \& Zufferey, 2015; World Health Organisation, 2017), and whether it is part of the responsibility of a residential facility to attend to the intimacy and sexuality of a resident (Elias \& Ryan, 2011; Everett, 2008), particularly for gender and sexually diverse residents (Ansara, 2015; Hafford-Letchfield et al., 2018). The notions of human rights and sexual citizenship have been introduced into the discourse (Birt et al., 2017; Kelly \& Innes, 2013; Kontos et al., 2016; Simpson et al., 2017a, b). We believe the needs vs. rights debate distracts from a resident-focused approach which places well-being at the centre of care. In both the need and right perspectives, sexuality and intimacy are problematised, rather than perceived as an integral part of an individual's life, giving them meaning and purpose. A salutogenic approach (Greene \& Cohen, 2005) contextualises relationship, intimacy, and sexuality as part of an overall person-centred approach which focuses on well-being, strengths, resilience, and quality of life of an individual. In other words, we propose that the need and right debate distracts from what we propose should be the primary purpose of residential facilities: supporting an individual to thrive, or as one of our participants put it, living their lives until they do not. 
One of the complexities in the field is the ethics of consent (Mahieu \& Gastmans, 2012), particularly for persons who have become intellectually compromised because of dementias (Cook et al., 2017; Tabak \& Shemesh-Kigli, 2006; Tenenbaum, 2009; Villar et al., 2014). The growing population of older persons and the changing profile, values, and expectations of persons entering residential aged care (Bowers, 2017, January 26)—including people who live in an era where marriage equality is an increasing reality, and sex work is not criminal-bring an added urgency to this research, policy, and practice area.

\section{Methods}

The present study was a two-arm mixed-method cross-sectional study using a concurrent triangulation design. Data were collected in 2018 and 2019 by core project staff and qualified contracted project 'ambassadors' in their local regions prior to the national Covid-19 lockdown. The study was fully reviewed and received approval by the Massey University Human Ethics Committee-Northern (number NOR18/25). Recruitment of sites was stratified by region and by size proportionate to the number of RAC facilities in the size band throughout the country. Although we originally planned a probability sample, for various reasons (mostly not directly related to the study), we had 29.6\% success rate in recruiting sites, and we must now call this a sample of convenience. For the quantitative arm, the research team developed and validated a 20-question knowledge, attitude, and behaviour (KAB) survey with 5-point Likert scale responses (Cronbach's alpha for the entire survey was $\alpha=0.81$ ), two additional scenario questions, and a free response area. Surveys were distributed to staff at routine facility staff meetings; 433 surveys were completed and returned from 35 RACFs through New Zealand. Surveys were returned to sealed marked boxes which were later collected by project staff, or in more remote areas surveys were posted to the project in Freepost envelopes provided. The survey was anonymous and self-administered. The estimated survey response rate was $62.5 \%$ (we do not know exactly how many surveys were distributed to and returned by night shift staff). The data collected from the surveys were cleaned and coded, entered into SPSS statistical software (IBM Corp., 2017) for analysis, and the probability threshold was set at $\alpha=.05$. Data were checked for accuracy, missing data, outliers, and normality before statistical analyses were conducted. There were 40 missing item responses out of a possible 8660 , yielding a missing response rate of $0.4 \%$; missing items were coded with a neutral response (Downey \& King, 1998).

The second arm consisted of semi-structured interviews with participants recruited from these sites. Thorne's (2016) methodological approach, interpretive description, was used. This methodology draws from factual material and social constructionist analysis to aid investigation of the 'messy' world of healthcare. The social constructionist paradigm focuses on how meanings are created, sustained, negotiated, and interrupted (Burr, 2015). Project staff conducted 61 interviews with 77 participants recruited from the 35 participating RACFs. For cultural reasons some staff preferred to be interviewed in a group; this is not unusual in research in Aotearoa New Zealand, particularly among participants from Pacific Island nations. Interviews were completed as follows:

- staff, 19 individual interviews, and four groups with a total of 17 additional people;

- residents, 26 interviews with 28 people (there were two couples who wished to be interviewed together;

- family members, 12 interviews with 13 people.

The length of the interviews depended on participant engagement and fatigue; the shortest was $20 \mathrm{~min}$, and the longest was several hours over 2 days. Data were transcribed but not member checked (we felt that providing transcripts to residents living in situations where staff have free access to their personal living spaces would risk compromising their confidentiality). Key themes were identified independently by all five members of the core research team, then cross-checked and agreed; this interrater reliability increased the rigour of the coding and data analysis (Fereday \& Muir-Cochrane, 2006). An indigenous researcher conducted interviews with Māori, who also consulted with an expert in the coding and analysis of Māori data (Pere \& Barnes, 2009). The initial technical report was also peer reviewed by a community advisory panel which included experienced researchers, practitioners, and sexuality educators in the aged care field.

\section{Results}

\section{Profile of Survey Respondents}

We achieved our goal of recruiting participating sites nationally proportionate to the size of the facility despite some secular challenges (including a major bushfire in one region where much of the population was evacuated, and the mosque shooting in Christchurch, both of which occurred as we were about to launch the study in those regions). Age groups were roughly equally represented in the survey respondents, with the greatest number $(n=97$, $25.1 \%$ ) being recorded in the 51-60-year-old age group. Slightly more than half $(n=217,55.9 \%)$ of respondents identified their role as health care assistant, which is an entry level role requiring minimal formal education; 35 $(9.0 \%)$ were managers, $66(17.0 \%)$ were nurses, and 70 
(18.1\%) identified their roles as something else (social worker, occupational therapist, diversional [recreational] therapist, etc.).

There are cultural issues in aged care unique to New Zealand: for instance, while $85 \%$ of RAC residents identify as New Zealand European, and an estimated 5.5\% are Māori (New Zealand Labour Party, 2010), 44\% of staff identify as other than New Zealand European, including 10\% who identify as Māori, and $10 \%$ Pasifika (Thorton, 2010; we were unable to locate more recent data). Ethnic disparities between residents and the workforce, and within staff groups, are important because sexuality and culture are intrinsically linked (Aggleton et al., 2012). In the present study, nearly half of the survey respondents identified themselves as New Zealand European ( $n=151,48.7 \%)$, followed by Asian ( $n=84,27.1 \%)$, Māori $(n=29,9.4 \%)$, other $(n=24,7.7 \%)$, Pasifika $(n=15,4.8 \%)$, and Black African ( $n=7,2.3 \%)$. Just over half $(n=209,54.0 \%)$ of respondents said their country of origin was New Zealand, and 239 (61.6\%) said that English was their first language. Our survey sample therefore slightly under-represents Pasifika, which is not entirely surprising, since these groups are often reluctant to participant in survey research; we sought to capture Pasifika experiences more in interviews.

\section{Survey Questions}

Two of the survey items related to sex work and access to Internet pornography. Responses to the statement "My workplace should allow access to sex workers for residents who want this service, provided the resident is the one paying" were quite equally divided: $131(30.2 \%)$ agreed with the statement, 157 (36.3\%) disagreed, and 145 (33.5\%) were neutral; another way to consider these responses is that over two-thirds of respondents did not disagree with the statement. Opinions about residents' use of the Internet in private to meet their legal sexual interests (a question which asked about access to on-line pornography) were also quite equally divided: 148 (34.2\%) agreed, 133 (30.7\%) disagreed, and 152 (35.1\%) were neutral; again, two-thirds of respondents did not disagree. It is not possible from responses to the latter question to determine whether respondent attitudes were related to pornography in general or to resident use of the Internet to gain access to pornography, while in RAC, but there is no clear sentiment about this issue in either case. Our quantitative findings on these issues were therefore inconclusive.

\section{Interviews}

We anonymised the qualitative data with a short code; the first letter indicates staff $(\mathrm{S})$, resident $(\mathrm{R})$, or family member (F); the second is the serial order in which the interview was transcribed; and the final letter (M, F, or Group) indicates the gender of the interviewee (there were no self-identified trans interviewees).

\section{Sex Work}

The range of responses and reactions to sex work we saw in the survey data is also reflected in interviews. Some interview participants were unreservedly supportive, and some were very opposed. Others held more nuanced views. It is also clear that most staff understand that sexual desire can continue to occur throughout the lifespan into older age. When asked whether they would support access to sex workers for residents, some staff were very positive:

Yes, I would totally support that. If I thought there was need for that or a resident asked I would assist them to do that. (S5F)

I think that's a great idea. I think it's an awesome idea. I wonder, we've had quite a few...clients who were younger and more functional, or probably more physically capable as much as anything. Yeah, I think they really miss out, I think they miss out big time again in that way. (S1F)

For this particular resident, if tomorrow he died or she died, I know that she had a good day; even having a massage, or sex with [a] sex worker, isn't that amazing that we have been part of that, that I advocated and facilitated that. She died happily. (S10M)

It's okay. I don't have a problem with that either. They have their needs as much as we do; young or old. Who are we to say no? (S20F)

One staff respondent said that she and some of her colleagues had "actually visited a massage parlour to actually see kind of how a room could be made nice" (S7F).

Some participants recognised that their reluctance to endorse sex workers for residents was because of their own feelings, but were prepared to acknowledge that access to sex workers was a 'right'.

Personally, I don't feel that comfortable with it myself, but it's their right, and so we are here to make sure that they are supported, happy, and they have their rights. (S24F)

Concerningly, many staff participants were not aware of their facility's policy on access to sex work. One staff member noted that she had re-read the policy in preparation for the interview and that re-reading the policy had helped her gain confidence, despite the fact that she was somewhat uncomfortable addressing issues of sexuality:

A: When I re-read [the policy] today, yeah, I thought it was good, because it reminds you about everybody's rights to have that intimacy and feel that living con- 
nection with other people; it's so important-it's important for their happiness. It reminds you that it doesn't matter how old you are, you still have those needs and desires. But how I would approach... whether I'm meant to instigate a conversation with somebody about how do you... whether that became part of my [facility] questionnaire; I don't know how comfortable I'd feel or not about it...I probably wouldn't feel that comfortable about it, but I'm also quite a sensing, caring... I'm quite an intuitive person, so if that moment was there and it was in my policy and I was allowed to... Do you know what I mean? I don't think I would do it without it being appropriate, but if it was in policy and I felt like there was just that little bit more that needed to be drawn out there, I think I would be able to do it. (S24F)

The above staff interviewee's comments highlight the importance of practical, possibly scenario-based education so that staff have opportunities to consider how to translate policy into practice. Still, policy did not exist in some facilities, or if it did, staff were unaware of it.

What happened was that every weekend he brings a younger sex worker. They would go to his room.

Q: And you know that that person was a sex worker? Mmm. [Nods] He tells us. He says, "I'm not going to do it during the weekdays. I'm going to do that on the weekend because there's less people. Perhaps you don't think I'm allowed to do that." I said to him, "Why not? You are entitled to that. We just need to make sure that we will not be disrupting other residents, other people". [...] But to be honest, we don't have a specific policy in regards to that. (S12F)

One manager had an interesting perspective on the sexual and intimate needs of residents, describing meeting these needs as a kind of care, akin to other intimate care performed by staff.

Q: What about when you have a gentleman or a woman for that matter, who has a sexual need that can't be met within the facility; have you come across that?

A: We did have one in this other facility I was working in, and we actually paid for him...it was a male; he paid but we arranged for him to have a female visitor, and again, 'Do not disturb sign;' same thing. It doesn't say why you don't want to be disturbed, it could be that you're having a sleep or whatever. Everyone had them, so you weren't unusual. You didn't draw attention to the fact [...] Every door had a 'Do not disturb' sign, and some of them had 'Care in progress', so what it intimated was that you were being washed or showered in your room, so please do not enter. So that was even more discrete. Because it was kind of a care that was in progress. (S22F)
Ignoring or dismissing the possibility that sex occurs in RACF may also have affected staff responses in the case of a resident who was also a small businesswoman:

We even had in that same [RAC] in the village, an elderly lady that was selling services from her home. We thought was quite funny. I'm not sure how we found out. I didn't want to ask, but that was quite funny. (S22F)

Not all staff or facilities were supportive, however.

I don't know what [Facility's] policy is on that. Because it's a Christian facility, a [Denomination] facility; I don't know how open they would be to that. I've worked in facilities in the past where the managers have had no problem, and it's a process that I've had to work through, and I've come to a place where I have no problem with it. I know I've said here off the cuff in the nurses' station, "Maybe we should get a hooker in", or, "Maybe we should let them get their leg over". And there's been laughing, but nothing's ever been followed through. So, I wouldn't know what [Facility's] official policy is. I would suspect it would be a no, but that's just mean. (S7F)

While religious affiliation was cited as a reason to oppose access to sex work by some participants, others had a somewhat different take about their religious beliefs. One staff participant identified very clearly as Christian, although she felt her faith required her not to judge other people.

Q: How do you reconcile your personal values with your professional values, if your personal values are quite different from your professional values?

A: Well at the end of the day I have to remember, if I'm looking at it, my personal values, I don't get to judge people, because Jesus is the judge of everybody, not me. My job is to love people, and I love them as they are, because that's how he loved them. I'm watching his example.

Q: So, your faith is a strong source; your Christian faith is a source of your values?

A: Absolutely.

Q: And yet in the workplace you have to kind of balance that?

A: Yeah. (S13F)

The claim that she did not judge was severely tested as she related an event that had occurred at her facility:

Q: Some facilities have policies that allow for the use of escorts and sex workers. What do you think?

A: When I started here, and in my early years of caregiving [...] I did the cleaning for a year or so, and they 
needed me for nightshift. And the reason they needed me for nightshift was because one of the staff members had been removed very swiftly, after it was discovered that she had been leaving the facility to do blow jobs for a gentleman [resident] in [another part of the facility] at a certain price.

Q: He would actually pay her?

A: Yes. There was sexual contact. The only reason she was found out was because she tried to put the price up, and he rang the manager. He rang the village manager and complained about the price going up. If she hadn't been so greedy she could have got away with it for a long time. (S13F)

What was offensive to this quite Christian interviewee was not so much that another staff person was providing sexual services to residents, but that she was greedy, and it was greed that caught her out.

Some staff participants were reluctant to support engaging with sex workers because of risks they associated with sex work, rather than sex work itself.

Well, I don't know. I really don't. We'd have to work a plan out for that. It would be the care leads and the manager, and the family, and the doctor probably, and everybody. Yeah, because you never know, he might expire. (S8F)

Mine's a bit no [to sex work], because that's inviting them to have infections. I mean, sexual infections [...] We don't know if they're really clean; how can you prove it? I mean, if I am a sex worker; how can I prove it to my client that I am clean? (S2Group)

I don't think [the owner-managers] would let call girls come to the place. Only because in the past a lot of call girls are associated with drugs and associated with gambling, and that could be quite dangerous in a place like ours, if they worked around. [...] It would be quite a big step for [the owner-managers] if they did let someone in. I think it would put everyone else in danger. But, if you're talking about if [a resident] really wanted to go outside, if they were escorted and everything, then that maybe something they would talk about. (S4F)

This same staff person's personal reluctance to endorse sex work came from a moral perspective of protecting the sex worker or the resident:

I haven't actually asked them if they would consider that. Although, I know that in the past, prior, just knowing work girls in the past, that's quite a hard one. I know they're doing their work. But then just with the values that [the owner-managers] have, that that could be quite damaging work to the girl in the end, in her mind. (S4F)

Q: And so for you [...] when you encounter a situation that is a dilemma about a resident wanting to have some kind of relationship or engage with a sex worker [...] do you speak with the families?

A: Yes [...] If it involves finance [...]

Q: What if it didn't involve money?

A: No, I don't have to.

Q: So, if there's no money involved, or the resident can pay themselves...

A: Yes, yes, yes. (S10M)

Policies and education about sex work for all staff, residents, and family members are important to staff. To deny the reality of resident sexuality, or imagining that sex and sex working do not occur, leaves residents vulnerable to financial and other kinds of exploitation. Unless professional boundaries are explicit in relation to sexual expression with residents, unqualified, unregulated, and even unethical staff may not be aware of problematic power relations in providing sexual services to residents.

Resident responses were divided between clear support of sex work (or stipulated out-calls only) and some clear objections. Importantly, a number of residents felt that staff opposition would be a key factor in whether or not access to sex work would be possible in their facility, regardless of the residents' own opinions.

A: Oooh no, a definite no. I think we have one man here who could be interested in having a prostitute.

Q: Do you feel that this would not be acceptable by the staff?

A: No. (R18F)

Q: If a resident wanted to pay for services, say from a sex worker or an escort, how do you think staff would view that?

A: Disgusting.

Q: Really?

A: Absolutely. Why do you need that?

Q: So, you don't think staff would understand the need that someone might have for that?

A: No, I don't think so. It's not a topic that they're even brought up; for example, [if they asked] "How do you cope with your sexuality?" and I might be honest with them, but it's never been asked.

Q: So, the whole subject of sexuality is taboo?

A: Absolutely taboo, yes.

Q: Would family or staff have any say in [your relationships]?

A: It just wouldn't happen. I mean, my family don't know that I go and pay for sexual whatever you call it - activity. They don't know that. I'd never tell them. 
The same with the staff here; I would never tell them. (R8M)

It is difficult to know whether the above participant (R8M) is speaking rhetorically, ironically, hypothetically, or whether he actually does use sex workers. In any case, his comments reflect what he thinks the views of staff will be about sex workers: that the entire topic is off-limits to discussion, since he believes staff would understand the entire topic as "disgusting." Other residents also formed their response based on the ways they thought staff would react.

Q: What about if a resident wanted to pay someone for sexual services, like get an escort to come into their room? You're looking very shocked. Or a sex worker come in. What do you think?

A: Geez. No, I don't.

Q: Do you think staff would be okay with that?

A: I don't know, you'd have to ask the staff. I'd be flabbergasted. I wouldn't want to know. (R24M)

I don't think that would go down very well at all. It would have to be a sneaky arrangement.

Q: "A sneaky arrangement"?

A: Yes, definitely, but it could happen.

Q: But your sense is that staff would not really be [supportive]?

A: No, I don't think they would approve at all. (R23F)

The question even seemed to put an idea into the mind of one female resident, who conflated the idea of sex work and party entertainment:

Okay. I wouldn't care about that. [...] I don't know whether the staff would know. I don't think they're involved enough with the residents to know. You could easily bring a sex worker in here. I wouldn't dream of having a sex worker visit me. I would have a stripper come to a party, and it's given me a good idea. I would dial up a stripper, but it wouldn't enter my consciousness to have a sex worker. And what I'm saying is not because I'm 83, but because I was born pre-anyone even thinking of sex working. Anyone born after 1970 might think of a sex worker. Our generation, or say pre-1950, we would never have thought of it [...] I like these toy boy fellas, you know, that's a much better idea, I wish I knew some around [City]. (R5F)

A few residents acknowledged that the practice was already going on and that they had taken advantage of it, or would like to do so.

Actually, they do that... I get the paper; it's in the paper. I might give her a ring to come and see me. I gave her a ring and she comes to see me. It wasn't easy of course. What can you do around here? But, she talked to me a bit. I gave her $\$ 80.00$. Too much.
Q: Did the staff know that you were doing that?

A: I think so. I didn't care really.

Q: You just organised that on your own?

A: Yeah... Yeah.... She was more fun than anything else. I was laughing all the time. (R3M)

Yeah, they can't stop you. I can't afford to pay for one.

Bugger it! (R6F)

Bringing a sex worker into the facility was too much for one male resident: far better to make it an out-call.

No, I wouldn't advise anybody thinking that way, to call in a prostitute. I can understand the feeling, but I think they'd be better to go outside. (R10M)

Several residents either completely opposed the idea of sex workers, or thought the very idea of sex workers in an RACF was simply unimaginable.

Well, I wouldn't like it no. As a Christian I wouldn't like it. I don't think if that was able to happen here that I would like to stay here. (R13F)

Some residents felt that engaging a sex worker would offend the religious or cultural sensibilities of staff. Their comments also highlighted the extent to which some residents have come to view their RACF as more of a workplace than their own home.

If I suggested that to some of the nurses, I think they would be actually be quite offended by it. Remember again, these are not native New Zealanders, these are people from, as I say, predominantly from the Philippines. The lady that you brought you, [Name], she's from the Philippines; her husband is in the Philippines. He's also a nurse. She wears a ring. I think they might find it a bit distasteful, yeah, but I don't know. They don't put it on their list of offerings. (R4M)

Not really sure about that, in so far as anything that seems to be breaking the rules would be frowned upon. While that's not a rule, that would seem to be... because a lot of these people are very religious [...] They come from South East Asia and places like that. They have what some would call Christian attitudes, which are very deeply embedded. They would very quickly take a stance on what you were doing. (R9M)

The latter comment (by R9M) suggests that some residents imagined there were policies or rules related to sexual expression where in fact there may not have been any; in the event, the resident was unsure. His assumption was that his life would be governed by staff attitudes. On the other hand, some residents thought that engaging a sex worker was none of the business of staff or anyone else.

I really don't think it's got anything to do with the staff, personally myself. That's a private thing. Who's 
to know? I mean, as long as it is done discreetly, who the heck is going to know? [...] I'm quite sure that [staff name] would be quite happy with it, providing they're saying, "As long as you keep it to yourself. Do it discreetly. You don't have to throw it in everyone's face". (R7F)

Well, that's their business, it doesn't involve me. I'm not interested, put it that way. I always like to try and live by the motto 'live and let live', as long as you don't interfere with me. (R19F)

Family member participants were generally more opposed to sex workers than staff and residents, and this may be because the idea of their older family member engaging with a sex worker was simply unimaginable. This is not surprising, since for some it may be the first time they had considered the possibility of a parent being sexual in any way, or with someone other than their other parent. Some family participants were concerned about financial and safety risks. A few family members had a supportive or live-andlet-live attitude, provided that residents were protected from physical or financial harm. We also found that some family members - particularly daughters, in our study - took on responsibilities that perhaps were not theirs to assume. Sex work did not fit in with their notion of a genteel care facility.

I wouldn't like that. No. I guess here, this is our first time dealing with a rest home, and because [Facility] is so little and it is like a home. It's just so lovely here. I couldn't imagine that happening here. (F2F)

I've never thought about it. I don't want to think about it. If that's what they want, then so be it. (F9F)

Everyone for their own choice, but myself, personally I couldn't do that, no. (F3F)

Q: There are some care homes in New Zealand that allow residents to access to escorts and sex workers.

A: Wow! [...] That creeps me out a little bit more. I didn't know that one. It does creep me out. I don't know. I have no respect for that industry or those people. I guess they would use protection and stuff like that, but I certainly would never allow my mother, no matter what state she was in mentally. My sister and I would never allow her to access those kinds of services [...]. (F8F)

That this daughter would assume that she had the right to intercede with her mother's decisions regardless of her cognitive ability highlights again the importance both of having a facility policy and of educating family members to that policy. It was clear some family members conceptualised older adults in residential care as post-sexual and therefore found it impossible to imagine how anything associated with sexual expression could be arranged.
They can come to the actual room? Well, they'd have to be vetted very well as in STDs and safe sex and all that sort of thing. I'm not sure about that one. I don't think that will ever happen because there's a lot of...I just can't see something like that happening in a rest home. $(\mathrm{F} 10 \mathrm{~F})$

I can't imagine that happening in the age group that people are in care. I can't see that that would happen [...] If someone wanted it to happen, I think that would be something that the people who run that facility, I don't think they would approve of that. That's my own personal view. I think that would be so remote. I can't imagine that happening. [...] I can't imagine it being "Hip-hip-hooray and here is having sex every day with a prostitute" [...] I find that a very strange question to be perfectly honest. (F4F)

However, some family members were perfectly happy for residents to have access to sex workers-provided it was safe, residents paid personally, and were protected from financial exploitation:

I've heard about this happening in not rest homes but retirement villages where they're living independent lives, or they get taken out of the retirement village to a place where they can. When you say access, does that mean they come and see them, or they go to see...? Q: Either way.

A: Either way? Oh, why not?

Q: We're of course talking about residents paying for it on their own, because it's not part of the facility's services.

A: Oh, God no, no, they'd have to pay. Good on them, as long as it's in a safe environment, that's all I would say, and people know where they are. Yeah, good on them. (F10F)

I have no problem with that at all actually, so long as the resident is being protected sexually and financially. Because in my Dad's case, Dad's got no concept of money, so she could say, "I'll just get it out of your wallet," and take everything. (F7F)

Some family members found the idea of sex work and conversation about sex quite difficult. Interestingly, one family member would have appreciated a conversation-or at least some introduction to the notion of sexuality - at the time their family member was oriented to the facility, which would have made later discussions easier.

It's really hard to kind of decide what I would... I find it just so difficult to imagine him ever, ever kind of going there really. It's quite difficult to think, what if he had asked me that?' I guess, I would have been 
confronted by it to be honest. I guess I would have tried to talk to one of the staff about it, but that would have been an awkward conversation to have. I guess it's the kind of thing that you sort of imagine maybe that might be part of the material that they give you at the outset; so that's kind of covered in some ways. So, that approach is not just something you have to make cold from like, "Guess what?!" (F5F)

Because of the unique position of Māori as the indigenous people of Aotearoa New Zealand, it is relevant to consider some Māori responses separately. Significantly fewer Māori supported facilities' providing access to sex workers for residents $(6 / 29,20.7 \%)$ compared with NZ Europeans (61/151, $58.3 \%$; $p=.05)$. It is possible that the influence of Christianity through colonisation could be contributing to some of the reticence to discuss or acknowledge openly things of a sexual or intimate nature, although three-quarters of Māori respondents identified themselves as having 'No religion'. However, there is also a deeper understanding of wairua (spirituality) for Māori which is related to the tapu or sacredness attributed to intimacy and sexuality. Within spirituality and tapu constructs, there is an understanding that there are greater forces than the individual and their individual rights or personal desires. An entire collective group, in both the physical and the spiritual worlds, is involved in such decision-making. Decisions to engage with the intimacy and sexuality have implications wider than the individual person, and therefore, what is important is wider than the individual. This understanding goes some way to exploring the complexity of Māori responses to our quite simplistic research questions.

\section{Other Sexual Expressions}

Staff also recognised residents' rights and needs to sexuality more generally.

Q: If a man said to you, "Look I'd like to masturbate most nights; could you provide me with some cream?" or something like that; and he's just going to be alone in his room with the door shut. Would you facilitate that?

A: Of course. I mean it's his right. It's his need. There's no reason why we would not be able to accommodate that one provided that it doesn't disrupt the other residents. (S12F)

One staff member also had in mind women's sexual needs, in the context of providing assistance if required:

Q: And, if a person came and said, "I've run out batteries for my vibrator". You would help them get new ones, and things like that?
A: Yes, that's fine. We can't deprive them for that, because that's what they need; if that's what makes them feel better. Yeah, we just leave [them to it]. Yeah, as long as they're not going, I mean, to hire someone like a sex worker. We still let them do that. We should also give that to them. (S2Group)

One manager described how education was used in her facility to help staff manage situations they may be uncomfortable with

I teach all of the staff intimacy in the elderly. So, everybody is aware that if they go into a room and a gentleman is masturbating, they just quietly back out, close the door and go back in half an hour. That's his right and so you don't get shocked or, "Oh, he did such and such", you just walk away. A lot of these people have had a normal sex life; their partner dies and it's cut off, but that doesn't take away the urges, the feelings, or the need. It's not offensive, and it's not dirty; it's just natural and normal. (S23F)

Our data show that facility leadership is key in forming both staff and resident attitudes towards sexuality.

\section{Conclusion}

Access to sex workers is happening in RAC facilities in Aotearoa New Zealand, if not in all facilities, at least in a number of them around the country, in urban, suburban, and rural areas. While staff in some facilities appear to be prepared to respond to resident requests for sex workers, a number of staff are not, and are looking to policies and management to provide guidance. Many staff have adopted the language of needs vs. rights which dominates the literature. The lack of consistency among staff is concerning and suggests a lack of facility policies and education to those policies. Facilities may not yet be ready to put resident access to sex workers on their 'list of offerings', but it is essential that facilities have policies in place to address access to sex workers. At a minimum, all residents and key family members should be made aware of existing facility policies at least at the time of admission so that residents are fully aware of their options, even if they choose not to use them. Some staff and family members were at a loss as to how to begin such a discussion. While some participants were matter-of-fact about the issue, and others even enthusiastic, the reactions of other participants indicated that the topic of sex work was beyond their imagination in the context of RAC facility. Preparatory education for all staff, and even residents and family, may pre-empt a crisis when the unimaginable occurs (Bentrott \& Margrett, 2017; Kontos et al., 2016; Simpson et al., 2017a, b; Villar et al., 2014). Such education should take into account the multilevel framework in which facilities operate, and the multifarious stakeholders in 
residential care. This is the first study of its kind in the unique and complex cultural environment of Aotearoa New Zealand. A salient contribution of this study is that it considers these issues in a policy context where sex work is legal, while at the same time recognising that simply because something is legal does not make it widely accepted.

\section{Policy Recommendations}

Not surprisingly, we propose that staff education and training on sexuality is essential, and staff education to sex work and the facility policy on access to sex workers are essential (Cook et al., 2018; Cook et al., 2017); this is an area that must be addressed by regulators. Facilities may also wish to make education on sexuality and ageing available in some way to residents, and even family members. Ensuring that everyone is informed, knowledgeable, trained, and safe will reduce the likelihood of residents' sexual expression being treated as problematic or scandalous, or worthy of public attention. If a facility chooses to make access to sex workers possible, it should be prepared to arrange sex work services in the same ways as it arranges other contracted intimate personal services (such as hairdressers, or manicurists). In our view, if a facility enables access to sex workers for residents of care facilities, then it would be best for that facility to develop a relationship with a regular group of providers and work with local sex work organisations (where they exist) to train this regular group on how to work safely and appropriately with older persons. Models for this exist as sexual assistance in some countries (Chrastina \& Večeřová, 2020; Geymonat, 2019).

We do not take a view on whether any individual facility should provide access to sex workers as a right of residents, but we do propose that facilities (and their governance boards) need to have the conversation, and make their position explicit to residents (and potential residents), staff, and family members. We support the observation of many participants that residents have a right to privacy, and as long as residents are competent to make financial decisions elsewhere in their lives, they have a right to spend their own money on sex workers without the need for the facility to notify the family, or to seek their permission. We also found that both staff and family members often have a hazy understanding of how legal authorities such as powers of attorney relate to residents' sexual expression, and therefore, this is a particular area that warrants clear policy and education (Bauer et al., 2014; Wiskerke \& Manthorpe, 2016). To include third parties unnecessarily on decisions about sex workers is at best institutional risk management, and at worst simply gossip. Finally, we propose that the discourse about resident intimacy and sexuality needs to move beyond needs and rights, and towards a person-centred, salutogenic approach: the key question needs to be how to provide the best person-centred care that will allow a resident to thrive for their entire life.
Acknowledgements We express our thanks to our Community Advisory Board for this project who advised us throughout and peerreviewed the project report.

Funding Funding for this study was provided by a three-year Royal Society Te Apārangi Marsden Fund/Te Pūtea Rangahau a Marsden grant number MAU 1723.

\section{Declaration}

Conflict of Interest The authors declare no competing interests.

\section{References}

Aggleton, P., Boyce, P., Moore, H. L., \& Parker, R. (2012). Understanding global sexualities: New frontiers (Eds.). Routledge.

Aguilar, R. A. (2017). Sexual expression of nursing home residents: Systematic review of the literature. Journal of Nursing Scholarship, 49(5), 470-477. https://doi.org/10.1111/jnu.12315

Ansara, Y. G. (2015). Challenging cisgenderism in the ageing and aged care sector: Meeting the needs of older people of trans and/or nonbinary experience. Australasian Journal on Ageing, 34(Suppl 2), 14-18. https://doi.org/10.1111/ajag.12278

Arndt, W. F., \& Gingrich, F. W. (1979). A Greek-English Lexicon of the New Testament and other early Christian literature ( 2 ed.). University of Chicago Press.

Bauer, M., Fetherstonhaugh, D., Tarzia, L., Nay, R., Wellman, D., \& Beattie, E. (2013). 'I always look under the bed for a man'. Needs and barriers to the expression of sexuality in residential aged care: The views of residents with and without dementia. Psychology and Sexuality, 4(3), 296-309. https://doi.org/10.1136/bmj.c810

Bauer, M., Haesler, E., \& Fetherstonhaugh, D. (2019). Organisational enablers and barriers to the recognition of sexuality in aged care: A systematic review. Journal of Nursing Management, 27(4), 858-868. https://doi.org/10.1111/jonm.12743

Bauer, M., Nay, R., Tarzia, L., Fetherstonhaugh, D., Wellman, D., \& Beattie, E. (2014). "We need to know what's going on": Views of family members toward the sexual expression of people with dementia in residential aged care. Dementia, 13(5), 571-585. https://doi.org/10.1177/1471301213479785

Bellamy, P. (2012). Prostitution law reform in New Zealand. New Zealand Parliament/Paremata Aotearoa. https://www.parliament.nz/ en/pb/research-papers/document/00PLSocRP12051/prostitutionlaw-reform-in-new-zealand

Bentrott, M. D., \& Margrett, J. A. (2017). Adopting a multilevel approach to protecting residents' rights to sexuality in the longterm care environment: Policies, staff training, and response strategies. Sexuality Research \& Social Policy, 14(1), 359-369. https:// doi.org/10.1007/s13178-016-0260-y

Birt, L., Poland, F., Csipke, E., \& Charlesworth, G. (2017). Shifting dementia discourses from deficit to active citizenship. Sociology of Health \& Illness, 39(2), 199-211. https://doi.org/10.1111/1467-9566.12530

Bowers, L. A. (2017). Boomers necessitate sexual expression policies, insurer says. McNight's Senior Living. Retrieved January 31 from http://www.mcknightsseniorliving.com/news/boomers-necessitatesexual-expression-policies-insurer-says/article/634229/

Brassolotto, J., Howard, L., Manduca-Barone, A. (2020). "If you do not find the world tasty and sexy, you are out of touch with the most important things in life": Resident and family member perspectives on sexual expression in continuing care. Journal of Aging Studies, 53. https://doi.org/10.1016/j.jaging.2020.100849

Burr, V. (2015). Social constructionism (3rd ed.). Routledge. 
Chrastina, J., \& Večeřová, H. (2020). Supporting sexuality in adults with intellectual disability: A short review. Sexuality and Disability, 38, 285-298. https://doi.org/10.1007/s11195-018-9546-8

Cook, C. M., Schouten, V., \& Henrickson, M. (2018). Ethical underpinnings of sexuality policies in aged care: Centralising dignity. Ethics and Social Welfare. https://doi.org/10.1080/17496535. 2018.1512642

Cook, C. M., Schouten, V., Henrickson, M., \& McDonald, S. (2017). Ethics, intimacy and sexuality in aged care. Journal of Advanced Nursing, 73(12), 3017-3027. https://doi.org/10. 1111/jan.13361

Downey, R. G., \& King, C. V. (1998). Missing data in Likert ratings: A comparison of replacement methods. Journal of General Psychology, 1025(175-191). https://doi.org/10.1080/00221309809595542

Elias, J., \& Ryan, A. (2011). A review and commentary on the factors that influence expressions of sexuality by older people in care homes. Journal of Clinical Nursing, 20(11-12), 1668-1676. https://doi.org/10.1111/j.1365-2702.2010.03409.x

Everett, B. (2008). Supporting sexual activity in long-term care. Nursing Ethics, 15(1), 87-96. https://doi.org/10.1177/0969733007083937

Fereday, J., \& Muir-Cochrane, E. (2006). Demonstrating rigor using thematic analysis: A hybrid approach of inductive and deductive coding and theme development. International Journal of Qualitative Methods, 5(1), 80-92.

Frankowski, A. C., \& Clark, L. J. (2009). Sexuality and intimacy in assisted living: Residents' perspectives and experiences. Sexuality Research \& Social Policy, 6(4), 25-37.

Gewirtz-Meydan, A., Hafford-Letchfield, T., Ayalon, L., Benyamini, Y., Biermann, V., Coffey, A., Jackson, J., Phelan, A., Voß, P., Zeman, M. G., \& Zeman, Z. (2019). How do older people discuss their own sexuality? A systematic review of qualitative research studies. Culture, Health \& Sexuality, 21(3), 293-308. https://doi. org/10.1080/13691058.2018.1465203

Geymonat, G. G. (2019). Disability rights meet sex workers' rights: The making of sexual assistance in Europe. Sexuality Research \& Social Policy, 16, 214-226. https://doi.org/10.1007/ s13178-019-0377-x

Greene, R. R., \& Cohen, H. L. (2005). Social work with older adults and their families: Changing practice paradigms. Families in Society, 86(3), 367-373. https://doi.org/10.1606/1044-3894.3434

Hafford-Letchfield, T., Simpson, P., Willis, P., \& Almack, K. (2018). Developing inclusive residential care for older lesbian, gay, bisexual and trans (LGBT) people: An evaluation of the Care Home Challenge action research project. Health and Social Care in the Community, 26(2), e312-e320. https://doi.org/10.1111/hsc.12521

Howard, L., Brassolotto, J., \& Manduca-Barone, A. (2019). Navigating tensions about resident sexual expression in Alberta's continuing care homes: A qualitative study of leaders' experiences. Sexuality Research \& Social Policy. https://doi.org/10.1007/ s13178-019-00421-0

IBM Corp. (2017). IBM SPSS Statistics for Windows, Version 25.0. IBM Corp.

Kelly, F., \& Innes, A. (2013). Human rights, citizenship and dementia care nursing. International Journal of Older People Nursing, 8(1), 61-70. https://doi.org/10.1111/j.1748-3743.2011.00308.x

Kontos, P., Grigorovich, A., Kontos, A., \& Miller, K. (2016). Citizenship, human rights, and dementia: Towards a new embodied relational ethic of sexuality. Dementia, 15(3), 315-329. https:// doi.org/10.1177/1471301216636258

Mahieu, L., \& Gastmans, C. (2012). Sexuality in institutionalized elderly persons: A systematic review of argument-based ethics literature. International Psychogeriatrics, 24(3), 346-357. https:// doi.org/10.1017/S1044640211001542

Ministry of Social Development/Te Manatu Whakahiato Ora. (n.d.). An Ageing Population. http://www.msd.govt.nz/what-we-can-do/ seniorcitizens/positive-ageing/trends/ageing-population.html
New Zealand Labour Party. (2010). A report into aged care: What does the future hold for older New Zealanders? https://www.labour.org. nz/sites/default/files/Aged\%20Care\%20Report.pdf

New Zealand Parliament. (2003). Prostitution Reform Act 2003. Retrieved August 6 from http://www.legislation.govt.nz/act/public/2003/0028/latest/DLM197815.html

New Zealand Prostitutes Collective [NZPC]. (n.d.). The New Zealand model. Retrieved August 6 from https://www.nzpc.org.nz/TheNew-Zealand-Model

Pere, L., \& Barnes, A. (2009). New learnings from old understandings: Conducting qualitative research with Mäori. Qualitative Social Work, 8(4), 449-467. https://doi.org/10.1177/1473325009345796

Rowntree, M. R., \& Zufferey, C. (2015). Need or right: Sexual expression and intimacy in aged care. Journal of Aging Studies, 35, 20-25. https://doi.org/10.1016/j.jaging.2015.07.003

Simpson, P., Brown Wilson, C., Brown, L. J. E., Dickinson, T., \& Horne, M. (2017a). The challenges and opportunities in researching intimacy and sexuality in care homes accommodating older people: A feasibility study. Journal of Advanced Nursing, 73(1), 127-137. https://doi.org/10.1111/jan.13080

Simpson, P., Brown Wilson, C., Brown, L. J. E., Dickinson, T., \& Horne, M. (2018). 'We've had our sex life way back': Older care home residents, sexuality and intimacy. Ageing \& Society, 38(1478-1501). https://doi.org/10.1017/S0144686X17000101

Simpson, P., Horne, M., Brown, L. J. E., Wilson, C. B., Dickinson, T., \& Torkington, K. (2017b). Old(er) care home residents and sexual/intimate citizenship. Ageing \& Society, 37(2), 243-265. https://doi.org/10.1017/50144686X15001105

StatsNZ/Tatauranga Aotearoa. (2019). New Zealand's population reflects growing diversity. Retrieved August 6 from https://www. stats.govt.nz/news/new-zealands-population-reflects-growingdiversity

Tabak, N., \& Shemesh-Kigli, R. (2006). Sexuality and Alzheimer's disease: Can the two go together? Nursing Forum, 41(4), 158-166.

Tenenbaum, E. (2009). To be or to exist: Standards for deciding whether dementia patients in nursing homes should engage in intimacy, sex and adultery. Indiana Law Review, 42(3). Retrieved February 8, 2010, from http://ssrn.com/abstract=1470316

Thorne, S. (2016). Interpretive description: Qualitative research for applied practice (2nd ed.). Routledge.

Thorton, G. (2010). Aged Residential Care Service Review. https:// www.grantthornton.co.nz/globalassets/1.-member-firms/newzealand/pdfs/aged-residential-care-service-review.pdf

Thys, K., Mahieu, L., Cavolo, A., Hensen, C., Dierckx de Casterlé, B., \& Gastmans, C. (2019). Nurses' experiences and reactions towards intimacy and sexuality expressions by nursing home residents: A qualitative study. Journal of Clinical Nursing, 28, 836-849. https://doi.org/10.1111/jocn.14680

Villar, F., Celdrán, M., Fabà, J., \& Serrat, R. (2014). Staff attitudes towards sexual relationships among institutionalized people with dementia: Does an extreme cautionary stance predominate? International Psychogeriatrics, 26(3), 403-412. https://doi.org/ $10.1017 / \mathrm{S} 1041610213002342$

Wiskerke, E., \& Manthorpe, J. (2016). New relationships and intimacy in long-term care: The views of relatives of residents with dementia and care home staff. Dementia, 17(4), 405-422. https://doi.org/ $10.1177 / 1471301216647814$

World Health Organisation. (2017). Sexual and Reproductive Health. http://www.who.int/reproductivehealth/topics/sexual_health/sh_ definitions/en/

Publisher's Note Springer Nature remains neutral with regard to jurisdictional claims in published maps and institutional affiliations. 